\title{
Evaluation of some cellular and mitochondrial parameters in HT1080 cell line in response to the Ginger extract and one of its components: 6-shogaol
}

\section{INTRODUCTION}

Ginger (Zingiber officinale Roscoe, Zingiberaceae) has been used for thousands of years as a spice, and it has been considered to be an important ingredient in traditional Chinese medicine for the treatment of certain diseases, such as diabetes, cardiovascular diseases, rheumatism, and cancer [1]. In the last decade, there has also been progress in the study of other biological properties of ginger, such as its antifungal and antimicrobial ability. Interestingly, many studies have focused on the antioxidant, anti-inflammatory, and antitumor capacity, However, to date the molecular mechanisms through which ginger could exert this activity are still not fully understood [2].

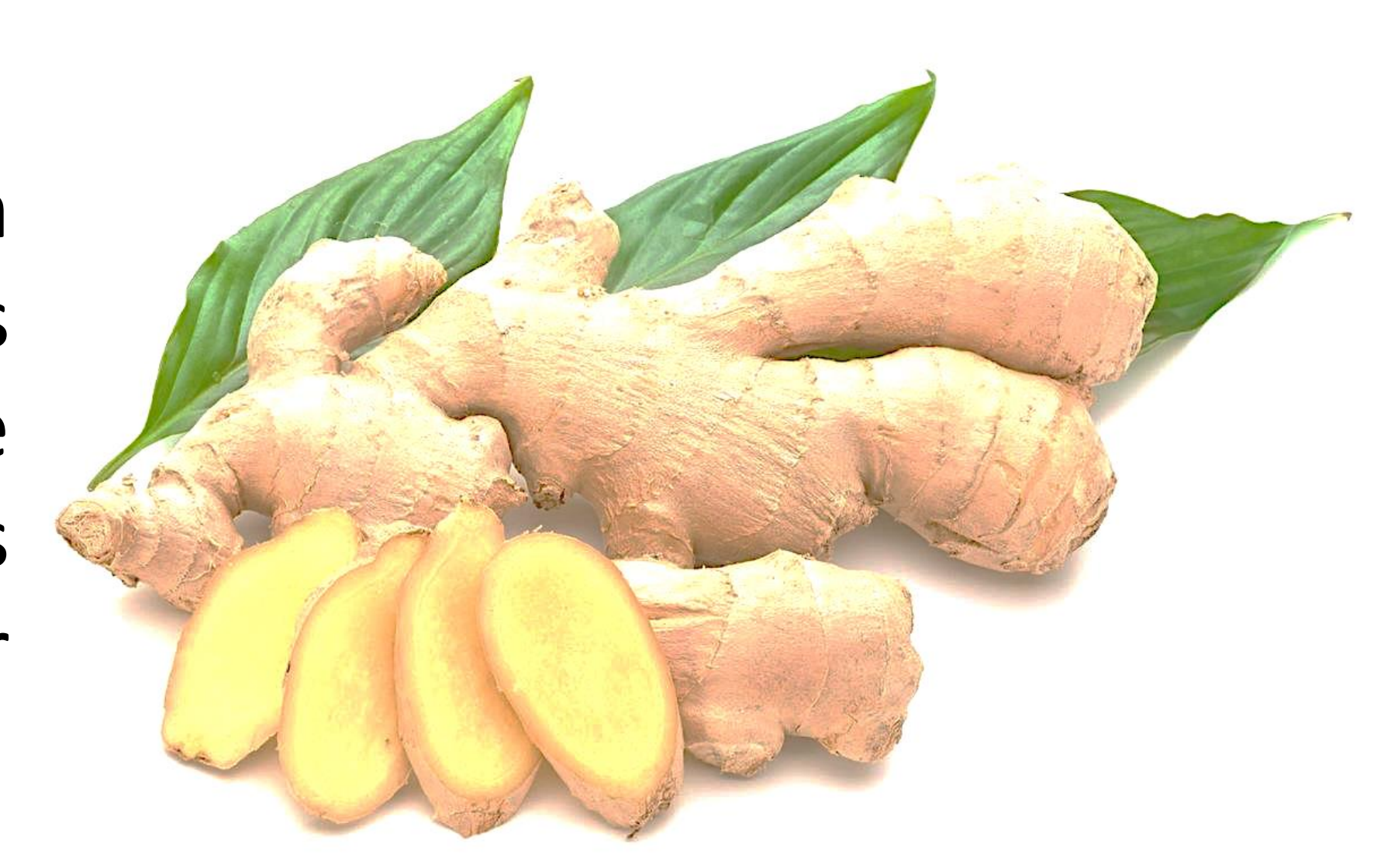

\section{MATERIAL AND METHODS}

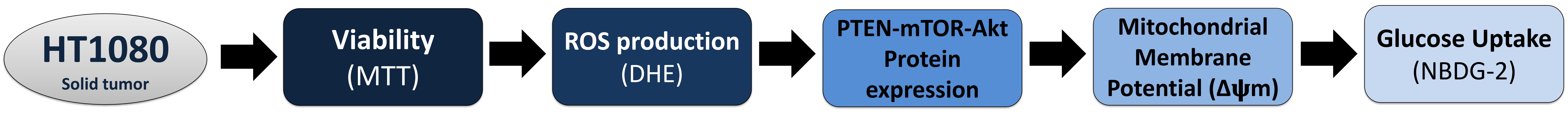

\section{RESULTS}

*Viability

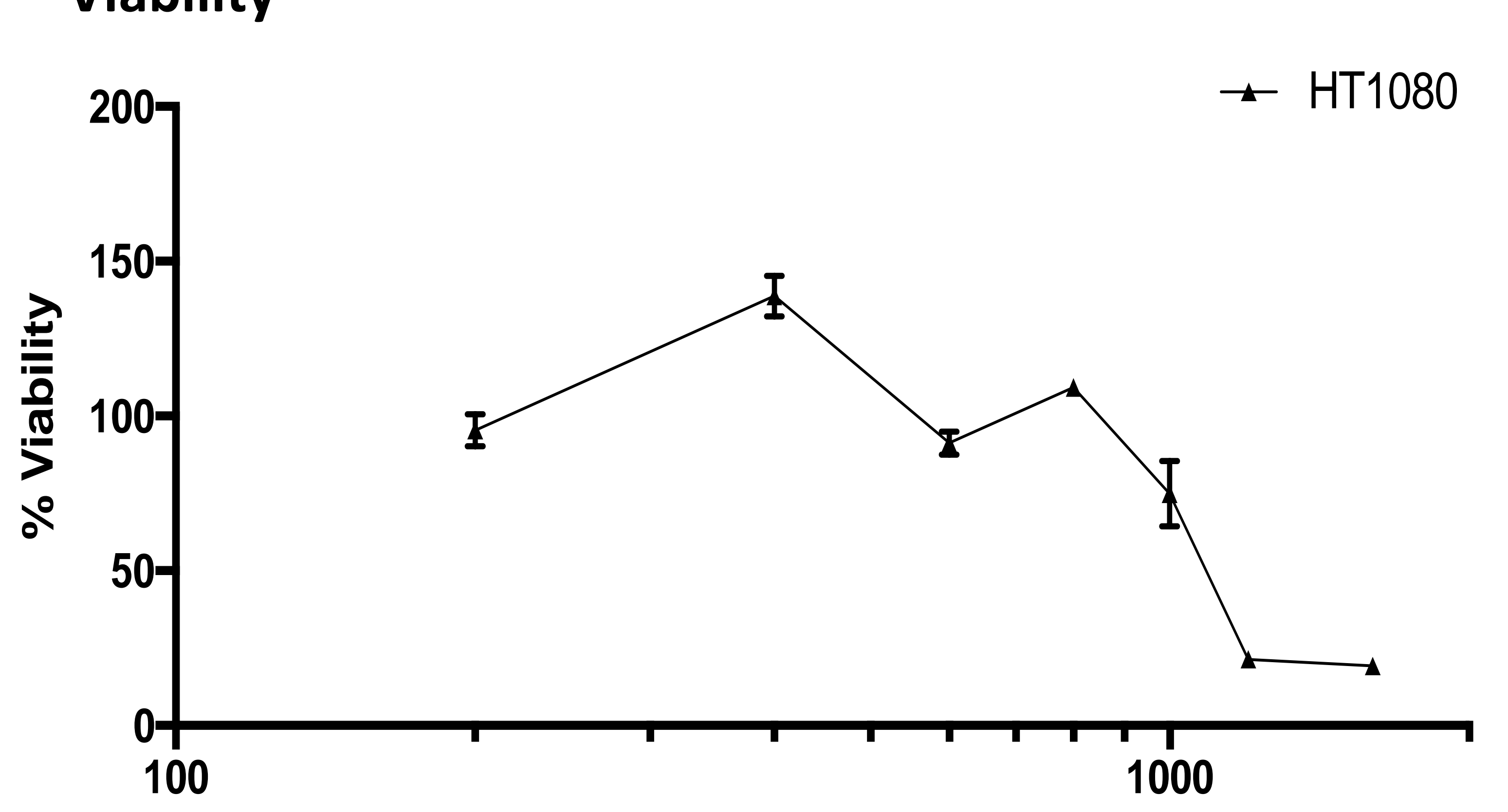

Ginger Extract ( $\mu \mathrm{g} / \mathrm{ml})$

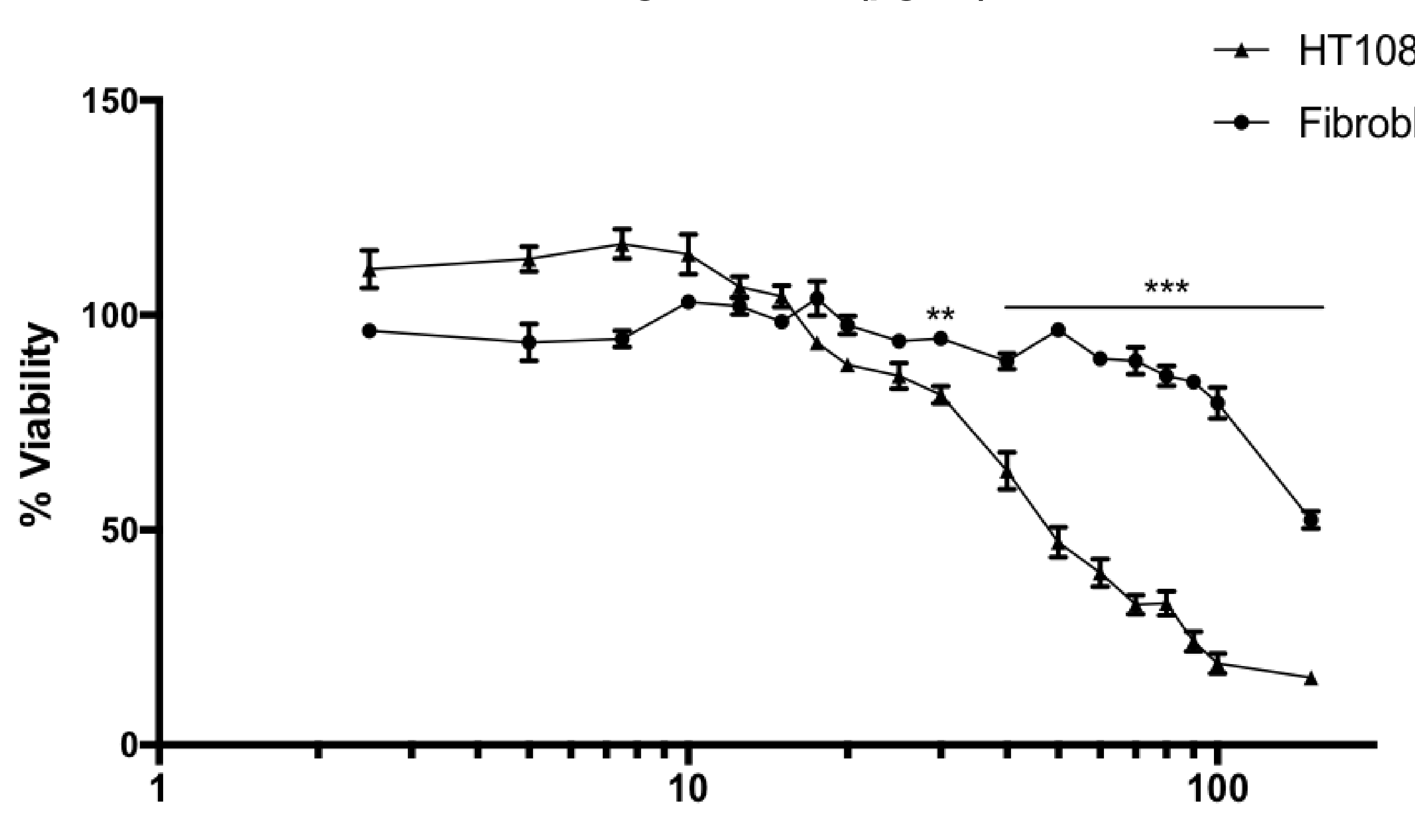

*ROS production
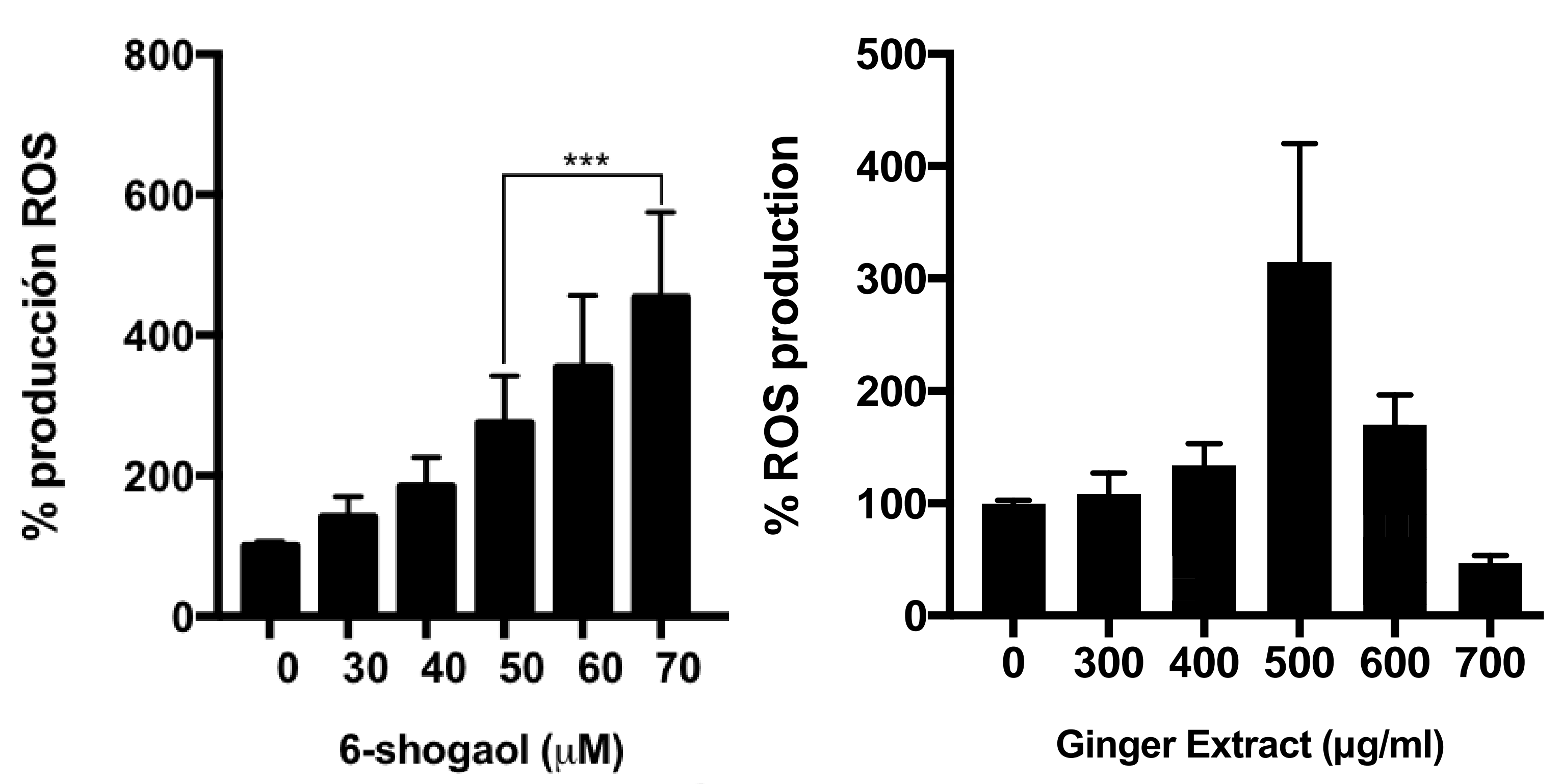

\section{CONCLUSION}

\section{*Protein expression}

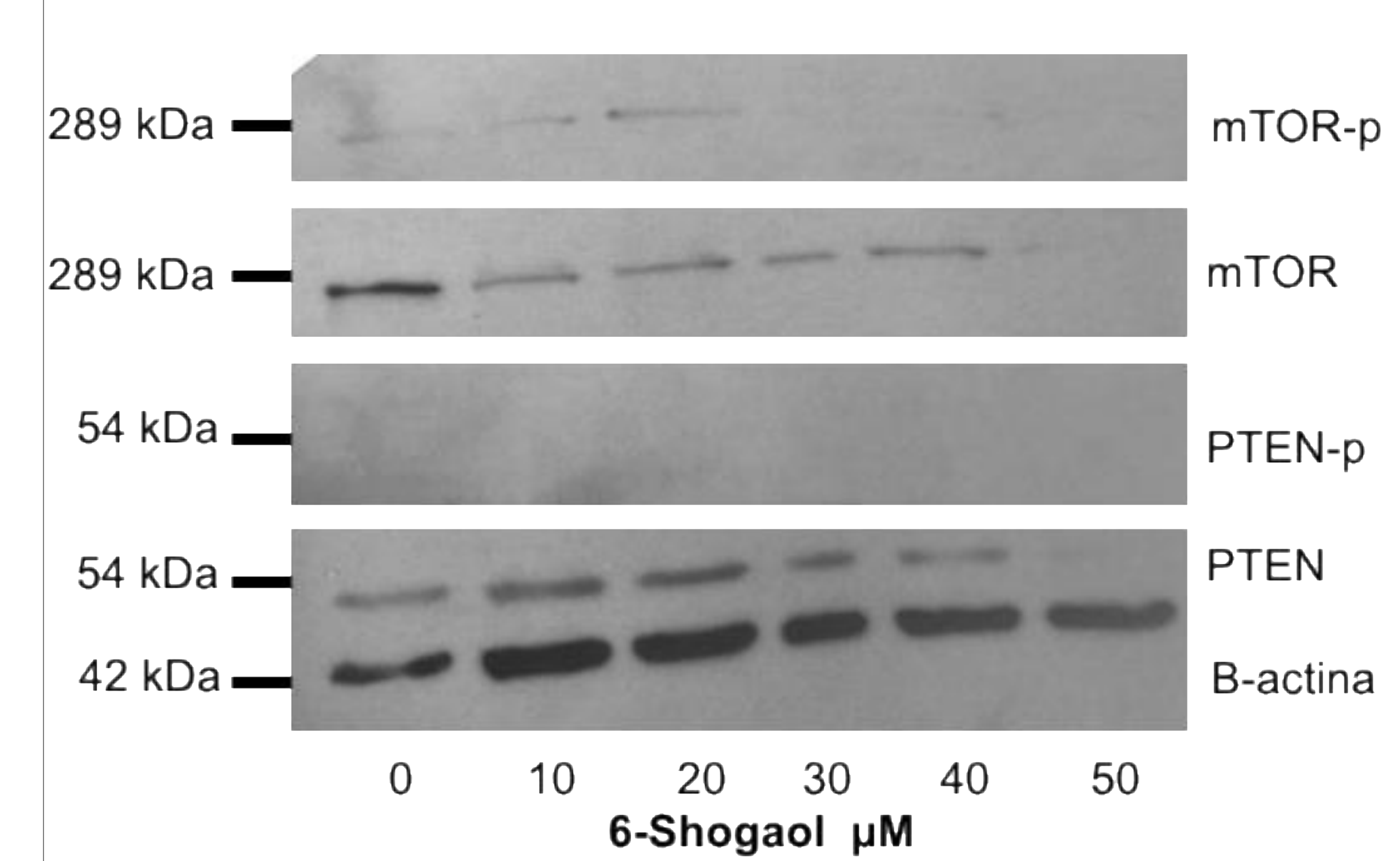

*Mitochondrial Membrane Potential $(\Delta \Psi \mathrm{m})$
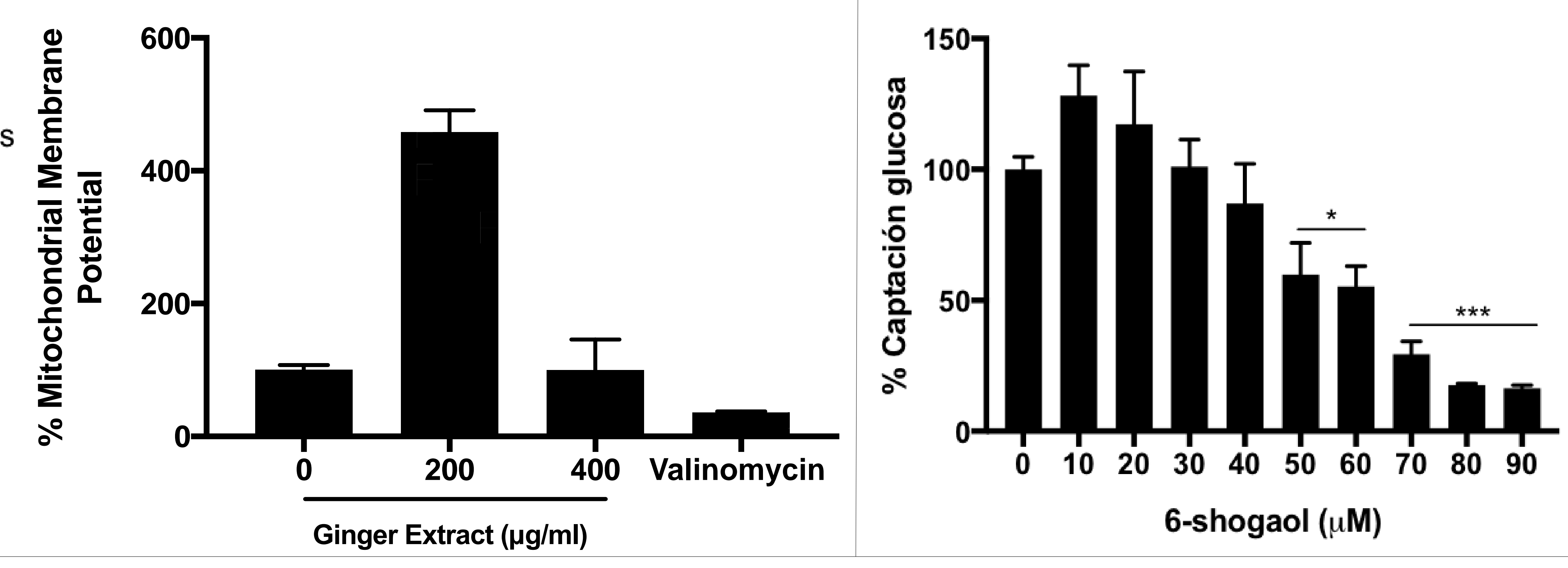

\section{PROPOSED MECHANISM OF ACTION}

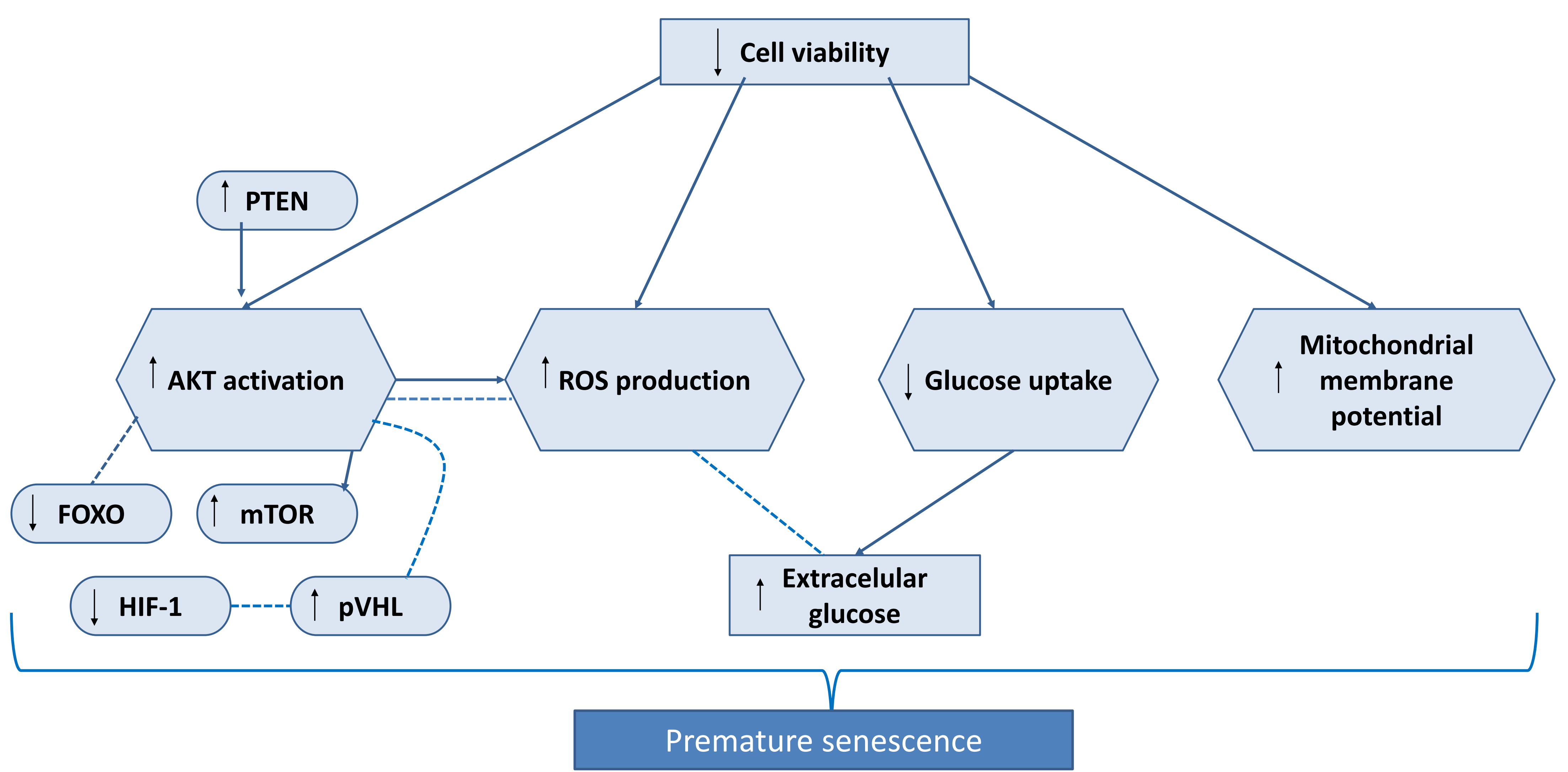

In conclusion, the results showed an increase in ROS production by the extract and 6-shogaol, which is associated with cell death. This may be related to the decrease in glucose as the main nutrient for tumor cells, which affected the polarization of the mitochondrial membrane. These two effects, together with the activation of the Akt signaling pathway, could induce cellular senescence.

\section{REFERENCES}

1. Romero, A., Forero, M., Sequeda-Castañeda, L. G., Grismaldo, A., Iglesias, J, CE
King Saud University - Science. https://doi.org/10.1016/j.jksus.2017.09.015

2. Romero-Arias, A. C., Sequeda-Castañeda, L. G., Aristizábal-Pachón, A. F., \& Morales, L. (2019). Effect of 6-shogaol on the glucose uptake and survival of HT1080 fibrosarcoma cells. Pharmaceuticals. https://doi.org/10.3390/ph12030131 